\title{
A percepção dos pescadores artesanais do Rio Gravatá (Navegantes, SC) sobre as mudanças ambientais e climáticas
}

\author{
The Gravatá river artesanal fishermen perceptions of environmental and \\ climate changes
}

\section{La perception des pêcheurs artisanaux de la rivière Gravatá (Navegantes, SC) sur les changements climatiques et environnementaux}

\section{La percepción de los pescadores artesanales del Río Gravatá (Navegantes, SC) sobre los cambios ambientales y climáticos}

\author{
Diego dos Santos ${ }^{1}$ \\ Fabiane Krumreich Siefert ${ }^{1}$ \\ Gilberto Friedenreich Santos ${ }^{1}$ \\ Cristiane Mansur Moraes de Souza ${ }^{1}$
}

Recebido em 04/09/2017; revisado e aprovado em 25/03/2018; aceito em 19/04/2018

DOI: http://dx.doi.org/10.20435/inter.v19i4.1705

\begin{abstract}
Resumo: As alterações no ambiente e no clima são uma realidade e influenciam a vida no planeta. Assim, o estudo tratou de verificar a percepção dos pescadores do Rio Gravatá, em Navegantes, SC, em relação à temática. A metodologia consistiu de análise documental e entrevistas. Os resultados observaram convergências e divergências entre os dados científicos e empíricos. As conclusões refletem a necessidade de adoção de ações mais sustentáveis e a participação da população local na tomada de decisões que afetarão seus cotidianos.
\end{abstract}

Palavras-chave: pescadores artesanais; Rio Gravatá; mudanças ambientais e climáticas; participação.

Abstract: The current environment and climate change are influencing life on Earth. Therefore, the focus of this article aims to analyze the perception of the fishermen in relation to this subject at Gravata's river in Navegantes, SC. The methodology consisted of documentary analysis and interviews. Results identify convergences and divergences between scientific and empirical data. The conclusions reflect the need to adopt more sustainable actions and the participation of the local population in the decision making that will affect their daily lives.

Keywords: artisanal fishermen; Gravatá River; environmental and climate changes; participation.

Résumé: Les changements dans l'environnement et le climat sont une réalité et affectent la vie sur la planète. Ainsi, l'étude a tenté de vérifier la perception des pêcheurs de la rivière Gravatá à Navegantes, SC, em ce qui concerne les thèmes. La méthodologie est l'analyse documentaire et des entrevues. Les résultats on montré des convergences entre les données scientifiques et empiriques. Les conclusions reflètent la nécessité d'adopter des actions plus durables et sur la participation des populations locales aux décisions qui affectent leur vie quotidienne.

Mots-clés: les pêcheurs artisanaux; Rivière Gravatá; l'environnement et le changement climatique; participation.

Resumen: Los cambios en el ambiente y en el clima son una realidad e influencian la vida en el planeta. Así, el estudio trató de verificar la percepción de los pescadores del Río Gravatá en Navegantes, SC, con relación a la temática. La metodología consistió en análisis documental y entrevistas. Los resultados observaron convergencias y divergencias entre los datos científicos y empíricos. Las conclusiones reflejan a necesidad de acciones más sostenibles y la participación de la población local en la toma de decisiones que afectarán a sus cotidianos.

Palabras clave: pescadores artesanales; Río Gravatá; cambios ambientales y climáticos; participación.

\footnotetext{
${ }^{1}$ Fundação Universidade Regional de Blumenau (FURB), Blumenau, Santa Catarina, Brasil.
} 


\section{INTRODUÇÃO}

A concepção mecanicista do universo atribui à existência humana demasiada importância, a ponto de considerar o homem a única referência válida, portanto, intrínseco a qualquer existência. Essa mentalidade conduz à presunção de que o homem é o senhor de tudo, detentor do direito de transformar, explorar, escravizar e servir-se da natureza (CAPRA, 1996). Esse entendimento pode estar conduzindo o globo ao caos, pois, segundo o IPCC (2014), é extremamente plausível que o homem seja o responsável principal pelo aquecimento global. Assim sendo, há que se sofisticar o debate, fazendo emergir a consciência de que as mudanças ambientais e climáticas não são apenas uma questão da natureza. Convergem-se também em uma problemática social e requerem, portanto, a participação da sociedade para enriquecer o debate e para a proposição de alternativas e soluções.

Ganuza et al. (2010) afirmam que qualquer método ou metodologia traça um caminho para colocar em perspectiva o que acontece ou aconteceria com o ser humano. É uma forma de entender o mundo, de relacionar os fatos e defini-los. É nesse sentido que a participação é importante, pois trata do poder de definir aquilo que é real. Essa participação, entretanto, precisa ser horizontal entre todos os envolvidos, construindo espaços e ferramentas para que o poder de decisão não seja monopolizado. Logo, as alternativas precisam ser pensadas conjuntamente em um ambiente compartilhado e democrático, baseado na ideia de cidadania que busca a transformação a partir da atuação de uma comunidade política plural, que percebe as distintas formas de entender a vida, ouve todos os atores, suas ações e seus conflitos. Nesse sentido, insiste-se na importância da construção social porque estas implicam ações e pensamentos, seres humanos e relações. Desse modo, há uma construção forte da realidade que deixa os indivíduos surpresos com o poder estruturante da participação. Isto porque tudo parte de um ponto de vista social, é fruto de convivência política e das relações humanas (GANUZA et al., 2010).

Nesse sentido, o objeto de estudo do artigo centrou-se na verificação da percepção dos pescadores da Vila do Rio Gravatá em Navegantes, SC, em relação às mudanças ambientais e climáticas que vêm ocorrendo. Da mesma forma, objetivou-se identificar as implicações desse fenômeno na pesca e no local onde os pescadores vivem. Isto, porque diversas pesquisas realizadas entre 1992 e 2016, em sambaquis e em sedimentos da planície Quaternária do Vale do Itajaí, confirmam que, mesmo antes da chegada dos imigrantes europeus na região, as mudanças climáticas já eram uma realidade. Essas mudanças produziam elevações do nível do mar e transgressões marinhas continente adentro com intensas alterações ambientais na costa catarinense (BRAUN, 2017). Por outro lado, as ações humanas também são um fator de desestabilização dos ecossistemas. Recursos oriundos das águas do Estado se encontram em situação alarmante. As infindáveis intervenções humanas têm contaminado, sobremaneira, rios e mares catarinenses. A proporção de poluição ronda os 50\% (CHAVES, 2016). Na mesma linha de considerações, caracterização ambiental realizada por Ferreira e Beaumord (2008) atesta que grande parte das áreas onde há rios e estuários na região de Itajaí (Navegantes e Itajaí estão separadas apenas pelo rio Itajaí-Açú) possuem elevado percentual de ambientes com qualidade razoável e ruim. As ações antropogênicas que mais influenciaram na qualidade ambiental local, afetando a integridade do meio físico-natural, foram os desmatamentos, os derramamentos de óleo, a piscicultura em escala industrial e as ocupações residenciais, sobretudo, na orla (FERREIRA; BEAUMORD, 2008). 
No intuito de ampliar o debate e a produção de conhecimento, realizou-se estudo de caso, de abordagem qualitativa, de cunho exploratório, pois visou-se compreender as percepções de uma comunidade específica, no caso, pescadores artesanais. Realizou-se então, breve pesquisa bibliográfica, entrevistas e cotejo dos dados disponibilizados pelo Painel Intergovernamental de Mudanças Climática (IPCC [na sigla em inglês], 2014), e, também, pelo Relatório de Impacto Ambiental de 2013, que discute a reestruturação do canal de acesso ao canal portuário do Rio Itajaí-açú, apontado pela comunidade entrevistada como fator antrópico de mudança no ambiente local. As entrevistas realizadas foram semiestruturadas, contando com um acervo de perguntas já pré-elaboradas, formuladas em blocos temáticos que abordavam a história de vida do entrevistado, ocupação da área de estudo, percepção sobre meio ambiente. Entrevistaramse quatro pescadores aleatoriamente, selecionados no dia da pesquisa de campo, realizada em Navegantes/SC, no ano de 2016. As entrevistas, devidamente autorizadas, foram gravadas, transcritas e analisadas, e os resultados incorporam este trabalho. Os pescadores artesanais estão identificados apenas com as iniciais do nome para evitar eventuais constrangimentos e desconfortos. O artigo está estruturado em parte introdutória, revisão bibliográfica, apresentação e discussão de dados e considerações finais.

\section{CONTEXTUALIZAÇÃO DA ÁREA PESQUISADA}

Navegantes, de colonização açoriana, é um município do litoral do Estado de Santa Catarina, Brasil (Figura 1). Foi assim nomeado em 17/12/1912 como uma homenagem aos homens do mar, aos pescadores e a Nossa Senhora, de quem os moradores eram devotos (PREFEITURA MUNICIPAL DE NAVEGANTES, s.d.). Foi bairro da cidade de Itajaí, tendo se desmembrado desta por meio da Lei Estadual n. 828, de 30/05/1962, tendo sido oficialmente instalado em 26/08 do mesmo ano (IBGE, 2017). Localizada na mesorregião do Vale do Itajaí, microrregião de Itajaí, distante $92 \mathrm{~km}$ da capital do Estado, Florianópolis. Possui território predominante plano, com clima subtropical mesotérmico úmido com oscilações entre $18^{\circ} \mathrm{C}$ e e $30^{\circ} \mathrm{C}$. Situa-se a 2 metros acima do nível do mar, na latitude 26053'56" sul, longitude 4839'15" oeste, predominando vegetação típica da Mata Atlântica tropical (PREFEITURA MUNICIPAL DE NAVEGANTES, s.d.). O município possui no tempo presente 77.137 habitantes, sendo os ali nascidos chamados "navegantinos" (IBGE, 2017). Tem área de 112,029 km² e densidade demográfica de 540,56 habitantes/ $/ \mathrm{km}^{2}$ (IBGE, 2017). 
Figura 1 - Localizaçã de Santa Catarina na América do Sul e do Município de Navegantes, SC, com destaque para a área de estudo
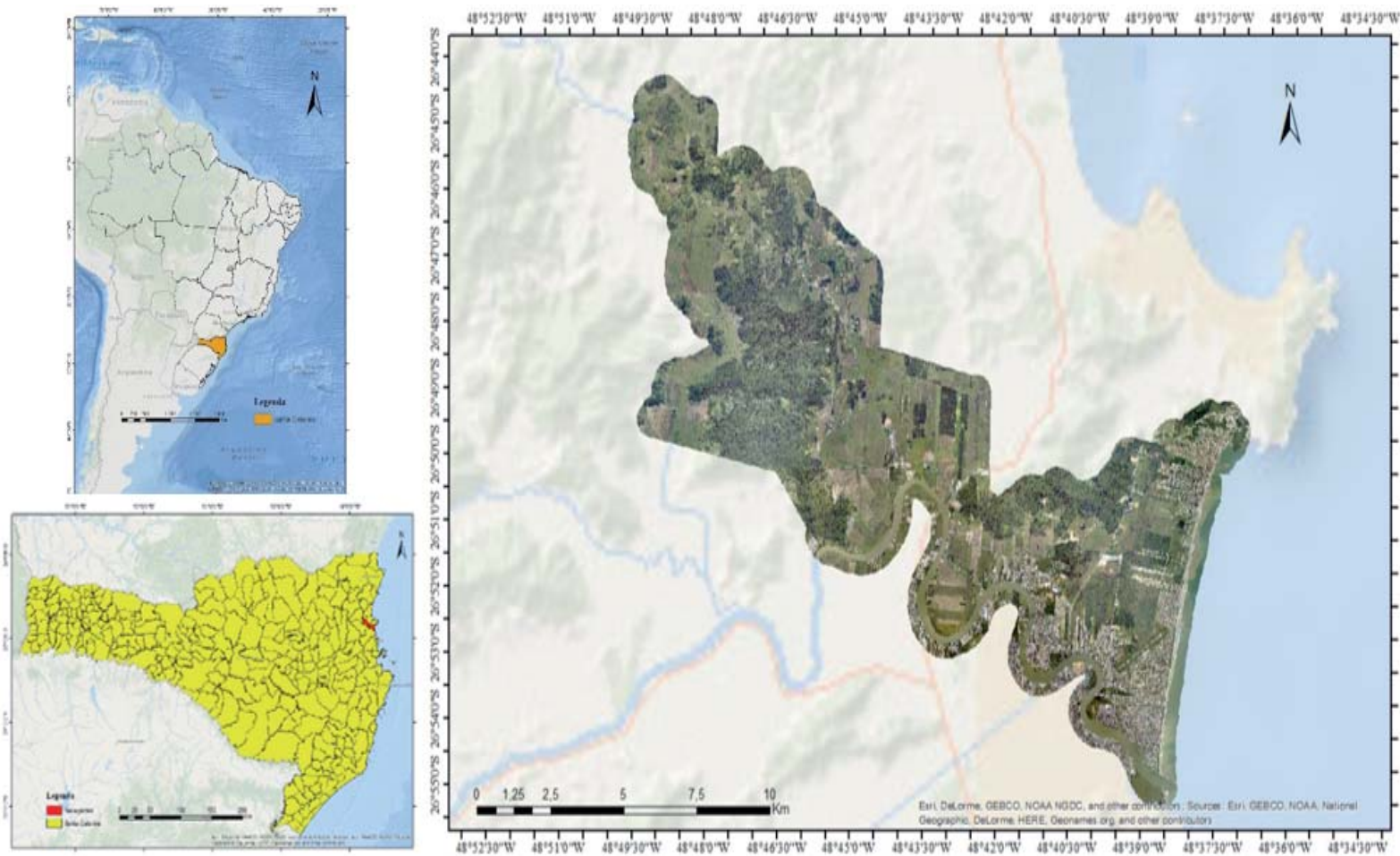

Fonte: Elaborado pelos autores a partir do shapefile do IBGE (2017).

\section{SÍNTESE DO RELATÓRIO IPCC 2014}

As mudanças climáticas são uma crescente preocupação entre destacados estudiosos e cientistas. Dada essa constante preocupação, da cooperação técnica entre a Organização Meteorológica Mundial e o Programa das Nações Unidas para o Meio Ambiente, entidades vinculadas à Organização das Nações Unidas (ONU), originou-se o Painel Intergovernamental de Mudanças Climáticas (IPCC). O IPCC é um órgão que compreende cientistas de todo o planeta. Ele efetua avaliações regulares sobre as mudanças climáticas do globo e é a principal referência do tema no plano internacional. Suas publicações tratam de aspectos científicos relacionados ao sistema climático e englobam, entre outras temáticas, as mudanças na temperatura terrestre, nos gases do efeito estufa, nas precipitações pluviométricas, nas geleiras e no nível das águas do mar, avaliações sobre a vulnerabilidade de sistemas naturais e alternativas para mitigação das alterações climáticas, por meio da limitação de emissão de gases do efeito estufa e práticas objetivando sua diminuição da atmosfera (IPCC, 2014).

Dados do quinto relatório do IPCC destacam que as mudanças climáticas são causadas, sobretudo pela ação antrópica. Conclusões de um dos grupos de trabalho do IPCC, afirmam que "é extremamente provável que a influência humana é a causa dominante do aquecimento observado na metade do século 20" (IPCC, 2014, p. 06). Já visível em todas as partes do mundo, tal aquecimento tem influência direta e irrestrita sobre toda a dinâmica terrestre e, paradoxalmente, sobre a própria humanidade. Isto, porque afeta a agricultura, a frequência de ocorrência de eventos extremos, a extinção de espécies, a biodiversidade etc. Ainda, provoca riscos à saúde humana, à segurança alimentar, aos recursos de água doce, aos sistemas costeiros e marinhos, ao combate à pobreza e riscos regionais. Conquanto o horizonte vislumbrado seja estarrecedor, 
o relatório apresenta inúmeras sugestões para atenuação dos efeitos devastadores, oriundos das alterações do clima. Na sequência, apresentar-se-ão as principais considerações, estratégias de adaptação e medidas de abrandamento publicadas pelos estudiosos do IPCC.

O relatório do IPCC, apresentado em 2014, afirma que, em função do aquecimento global provocado pela ação humana, sobretudo pela emissão de gás carbônico, já se pode constatar que as geleiras estão em processo de encolhimento. Essa situação altera os sistemas hidrológicos e afetam os recursos hídricos em termos de qualidade e quantidade. Para os estudiosos, essa confluência de fenômenos altera a vida marinha, aquática e terrestre, pois muda sua distribuição geográfica, seus padrões de migração, abundância e interações com o meio, provocando extinções. Dentre os fenômenos identificados pelas mudanças climáticas, o grupo de trabalho II do AR5 do IPCC (2014) destaca os impactos negativos na produção agrícola, com redução nas colheitas de arroz, soja, milho e trigo. Como consequência, há elevação de preços, o que representa ameaça à segurança alimentar (acesso à alimentação).

O Painel Intergovernamental destaca ainda que os impactos oriundos de eventos climáticos extremos, como, por exemplo, ondas de calor, secas, inundações, ciclones e incêndios florestais, revelam a significativa vulnerabilidade e a exposição de alguns ecossistemas - e de muitos sistemas humanos- à variabilidade climática atual. Tais impactos relacionados às alterações do clima incluem a mutação dos ecossistemas, a interrupção da produção de alimentos e abastecimento de água, danos a infraestruturas e assentamentos, aumento no número de doenças, mortalidade e consequências para a saúde mental e bem-estar humano. Ocorrências que poderiam suscitar o aumento no número de conflitos violentos. Outros riscos relacionados à mudança do clima incluem a exacerbação de aspectos estressores apresentando, muitas vezes, resultados negativos para os meios de vida, especialmente para as pessoas que vivem em situação de pobreza, pois essas situações seriam aprofundadas e/ou prolongadas com focos emergentes de fome (IPCC, 2014).

Diante do prognóstico de um cenário catastrófico, o IPCC apresenta medidas humanas para adaptação e abrandamento frente aos projetados impactos que um planeta aquecido para além do aceitável nos impõe. Dentre as estratégias de adaptação, o grupo de trabalho II do AR5 do IPCC (2014) enumera várias ações de mitigação, sempre vinculados aos processos socioeconômicos e de desenvolvimento sustentável, registrando que as estratégias variam de acordo com a região, bem como que as medidas não são estanques, isto é, não compreendem uma fórmula pré-pronta e aplicável indistintamente. Cada situação pode ensejar uma medida específica, aperfeiçoamento ou desenvolvimento de novas tecnologias. O relatório indica que os esforços para mitigação e adaptação devem partir dos indivíduos, com ampliação da participação das comunidades, famílias e sociedade civil e também de todas as esferas governamentais.

Indica-se, ainda, que, para reduzir a vulnerabilidade e exposição aos efeitos das mudanças climáticas, é imprescindível a adoção de múltiplas ações coordenadas, abrangendo o desenvolvimento humano (melhoria do acesso à educação, nutrição, facilidades de saúde, energia, acesso à moradia segura e estruturas para assentamentos humanos, redução das desigualdades entre gêneros e outras marginalizações), diminuição da pobreza (melhoria do acesso e controle de recursos locais, posse da terra, redução dos riscos de desastres, proteção social), melhoria da renda e diversificação do sustento, melhoria da infraestrutura com acesso à tecnologias limpas, aumento do poder de tomada de decisão, mudanças nos cultivos, na pecuária e nas práticas de aquicultura, investimento em gestão de riscos e desastres (sistemas de alerta, mapeamento de 
desastres e vulnerabilidades, diversidade dos recursos hídricos, melhoria da drenagem, abrigo para enchentes e ciclones, construção de códigos e práticas, gestão de tempestades e do desperdício de água, melhoramento da infraestrutura de transporte e rodovias) etc. (IPCC, 2014).

Outros mecanismos sustentáveis, aptos a adequar a vida às mudanças oriundas das alterações climáticas, incluem gestão ecossistêmica (manutenção de pântanos e espaços urbanos verdes, arborização costeira, gestão de reservatórios e bacias hidrográficas, redução de outros estressores dos ecossistemas e de habitats fragmentados, manutenção da diversidade genética), planejamento urbano (promoção da adequação de casas, infraestruturas e serviços, desenvolvimento de gestão para encostas e outras áreas de risco, planejamento e melhoria de programas urbanos, lei de zoneamento de terras, servidão, áreas de proteção), soluções de engenharia e opções de construções ecológicas (barragens para o mar e costa e estruturas de proteção, barreiras para enchentes, estocagem de água, melhoria do dreno, abrigo para ciclones, construção de códigos e práticas, gestão de tempestades e desperdício de água, melhoramento da infraestrutura de transporte e rodovias, casas flutuantes, ajustamento das fontes e usinas de eletricidade), opções tecnológicas (novas variedades de cultivo e de criação de animais, conhecimento indígena tradicional e local, tecnologias e métodos, irrigação eficiente, tecnologias para reuso de água, dessalinização, conservação da agricultura, estoque de comida e melhoria de sua conservação, mapeamento e monitoramento de desastres e vulnerabilidade, sistema de desastres, isolamento de prédios, técnicas de resfriamento mecânico e passivo, desenvolvimento, difusão e transferência de tecnologias) e restauração ecológica (conservação do solo, arborização e reflorestamentos). Por fim, incluem-se na trilha de afazeres para tentar reduzir as mudanças climáticas e como boas práticas para um desenvolvimento mais sustentável e, portanto, mais preocupado com o futuro do globo, a criação de políticas públicas e redes de serviço que contemplem a proteção social e conexões sociais seguras, banco de sementes e distribuição do excedente de comida, serviços de água e saneamento básico, cooperação público-privada, programas de vacinação, serviços públicos de saúde, aumento dos serviços de emergência médica, entre outras (IPCC, 2014).

\subsection{E os pescadores artesanais do Rio Gravatá, em Navegantes, SC, o que pensam das mudanças ambientais e climáticas?}

Conforme reportado pelo quinto relatório do IPCC (2014), o quadro é bastante desolador e exige atenção do mundo. As percepções dos pescadores do Rio Gravatá, em Navegantes/SC, embora empíricas, possuem pontos de convergência com o relatório científico. A maior concordância refere-se à ação antrópica como a ocorrência preponderante a desencadear as mudanças no ambiente.

O entrevistado M. (69 anos), afirma que sempre residiu na localidade. Filho de pescadores diz que "a vida inteira trabalhei na pesca. Com 13 anos já fui pra pesca". É casado e possui três filhos, sendo que a filha "é enfermeira. Tem outro que trabalha com cultivo de marisco e tem outro que trabalha assim com barco, compra camarão, vende camarão e tem barco de pesca". Os entrevistados L. (54 anos), S. (22 anos) e G. (56 anos) afirmam que nasceram respectivamente em Itajaí, Blumenau e no bairro de Gravatá. Sobre a família, S. (2016) respondeu que: "A minha família pra te dizer é tudo com pesca. Meus irmãos são pescadores, mas de barco grande. A mãe trabalha descascando camarão. Meu pai sempre com esse negócio de barco. Agora aposentado. Mas no geral é tudo pescador". O entrevistado G. (2016), por sua vez, esclarece que em sua família todos são "Pescador. A família tudo é pescador". 
Sobre a localidade onde moram, denominada de Bairro de Gravatá, atribuem o nome a uma vegetação e ao fato de que "naquele tempo elas, havia aquelas mulheres que fiavam, elas tiravam o fio para fiar então era um gravatá era tipo uma... vegetação" (M. 2016). Dos fios do Gravatá, o entrevistado M. afirma que se faziam as redes de pescar. Em semelhante sentido, G. (2016) expõe que "tinha muita planta aqui antigamente, se morava no meio dos gravatás. É uma planta, um tipo de vegetação". O nome origina-se da ocorrência da planta Gravatá, da família das bromélias, que era comum na região.

Sobre as mudanças que vêm ocorrendo no ambiente, inclusive a subida do nível do mar, o entrevistado M. afirma que elas decorrem, sobretudo, em função da ação humana. "O povo que tão vindo, invadindo" (M. 2016). A culpa não é "do mar. É do homem mesmo. Porque isso aqui a água salgada quando enchia, ela invadia isso tudo aqui, oh. Só ficava uma ilhinha ali que ela não ia. E o mais aqui ela enchia tudo. O Rio transbordava né, quando ela vinha, aí... hoje não. É tudo casa" (M. 2016). Para ele o mar apenas retoma o que é seu. Conta que já encontraram:

[...] siri numa pedra que tem lá em cima da praia. Lá eles fizeram uma casa e o mar carregou. Eu era... Que engraçado, tinha nove anos, ia fazer dez anos. Deu um [mar grosso] que carregou tudo. Daí carregou essa casa lá. Então hoje é cômodo. Se ele [o mar] voltar um dia ali aí as pessoas vão dizer que está avançando. Não, é que ele já teve ali. (M., 2016).

Para outro entrevistado o que atrapalha também é a ação humana, no caso, a ação governamental. Afirma que "o que tem interferido na nossa pesca é a dragagem do rio Itajaí ali, que tão aumentando, aí a draga vai lá fora, solta muita sujeira, toco, lama que nós pegamos tudo na rede, passa muito trabalho e os peixes fogem, acaba com o camarão também" (S., 2016). Existem, porém, pontos de divergência entre as afirmações do relatório do IPCC e as percepções dos pescadores do Rio Gravatá, localizado em Navegantes, SC. Dizem respeito, sobretudo, ao número de peixes e maior ocorrência de eventos climáticos extremos. Acerca do aquecimento global e do ambiente do entorno, afirmam que tudo está igual. "Sempre foi assim" (G., 2016). O entrevistado M. perguntado sobre a mesma temática foi peremptório: "Sempre foi assim". Acerca das ressacas que haviam ocorrido no litoral catarinense na semana anterior à entrevista, $\mathbf{M}$. informou que:

Sempre teve. Mesma coisa faz anos. Se te dizer que eu perdi um tio, sobrinho e um primo. Um mar grosso assim, uma maresia que deu assim e matou todos, os quatro que moravam aí. Já dava, antigamente dava. Então, pessoal hoje fala que está chegando ao final [dos tempos]. Não é que está chegando ao final [dos tempos], a mesma coisa que dava antigamente, dá hoje. Só que hoje o homem está destruindo mais a praia, tá né, calçando a praia, botando pedra e o mar não quer aquilo ali. O mar quer areia. (M., 2016).

Sobre a maior severidade das ressacas marítimas, em suas lembranças, estão inclusive mais fracas. "Antigamente era mais forte ainda, aqui pra nós. Mar mais violento. Acontece que o que deu agora, se fosse aquela que dava antigamente tinha acabado com isso tudo aí, derrubado esses prédios todos, porque a maré ficou muito alta" (M., 2016). Para S. (2016): "essa aí ainda foi pouco. Teve uma vez, em 2008, que deu uma enchente [...] e deixou tudo embaixo da água". Sobre esse aspecto, e de acordo com o ponto de vista dos pescadores entrevistados, os eventos parecem apenas se repetir; ora mais fortes, ora mais fracos, numa postura cíclica da natureza.

Sobre a diminuição no número e na diversidade de peixes e camarões parece não existir consenso. G. (2016), afirma que "A pesca antigamente já foi mais farta né!? Bem mais farta". Por sua vez, M. (2016) tem percepção diferente: "Aqui dá tudo. Dá pescado, dá corvina, dá cação. Tudo quanto é peixe". Sobre a quantidade: 
Tudo igual. Tudo igual. Ano passado deu, esse ano deu. Esse ano foi o ano que deu mais tainha desde quando eu era novinho [...] às vezes eles falam que [a pesca] fracassou, mas não é que fracassou. É que é muita embarcação demais. Só que essa aí oh, dessa aí, aqui é pouquinha. Mas vai na frente São Miguel, Navegantes, Camboriú, Armação tem mais de mil, acho, três mil embarcações. Aí é onde eles falam que fracassou a pesca. Mas não fracassou nada. Está a mesma coisa como antigamente. (M., 2016).

Para os pescadores do Rio Gravatá, parte dos problemas a serem enfrentados por eles relaciona-se para além dos fenômenos da natureza, com a ampliação do Complexo Portuário do Rio Itajaí-açú, em Itajaí e Navegantes, SC. Assim, para dar continuidade ao estudo relacionar-se-ão os impactos tanto positivos como negativos da reestruturação do canal de acesso ao complexo portuário do rio Itajaí-Açu, para o meio ambiente e para a pesca local.

\section{RELATÓRIO DE IMPACTO AMBIENTAL - RIMA, OBJETIVOS E INFLUÊNCIAS NA PESCA E NO MEIO AMBIENTE}

O Relatório de Impacto Ambiental (RIMA) traz um resumo e simplifica os estudos e dados contidos no Estudo de Impacto Ambiental (EIA) para a Reestruturação do Canal de Acesso ao Complexo Portuário do Rio Itajaí-açú. Seu foco está no projeto de reestruturação do sistema aquaviário do Complexo Portuário do rio Itajaí-açú, em Itajaí e Navegantes, SC. O relatório estabelece que esse Complexo se constitui como o mais importante e moderno complexo portuário do Estado de Santa Catarina, no entanto, apesar dessa realidade, a infraestrutura marítima do Complexo Portuário de Itajaí possui limitações ao acesso de navios modernos. Assim, há uma crescente demanda por adequações físicas que possibilitem a operação de navios mais eficientes e de maiores dimensões no Complexo.

Segundo o relatório, essas importantes adequações no sistema aquaviário manterão o Complexo Portuário do Itajaí em condições de concorrência com os portos da região de sua influência e em igualdade de condições, conforme segue:

Assim, para garantir a competitividade do Porto de Itajaí e dos demais terminais localizados no baixo estuário do rio Itajaí-Açu, apresenta-se o projeto de reestruturação de seu canal de acesso. As obras do Projeto preveem a instalação de uma nova bacia de manobra de navios (bacia de evolução) adentrando, em parte, no ambiente denominado Saco da Fazenda, em Itajaí. Esta área terá 265.1 metros de raio, e profundidade de 14 metros. O Projeto também prevê o reposicionamento do molhe norte para que o canal de acesso interno ao Porto seja alargado; e a contenção dos taludes do novo trecho, incluindo os da nova bacia de evolução. (SEP/PR, 2013, p. 9).

Assim, consta no relatório que as obras de adequação supracitadas foram analisadas no EIA, que subsidia o processo administrativo de licenciamento ambiental do empreendimento. $O$ objetivo principal deste estudo está em garantir a competitividade do Complexo Portuário do rio Itajaí-Açu, de modo que este possa atender as novas demandas de operação internacional. Para tanto, serão necessárias adequações na infraestrutura do sistema aquaviário, capacitando-o às novas especificidades e exigências do mercado logístico mundial. Discutiu-se muito no relatório a questão dessa adequação, no que se refere ao local adotado, tanto quanto à influência das obras de reestruturação do canal de acesso e da implantação da nova bacia de evolução do Complexo Portuário, para os municípios de Itajaí e Navegantes.

Ainda conforme dados contidos no relatório, essas obras incidirão diretamente sobre a cadeia produtiva econômica da região. Sendo assim, espera-se, como resultado positivo, a po- 
tencialização da movimentação financeira nos setores de comércio e serviços, assim como na geração de empregos diretos e indiretos. Dessa forma, tem-se também a justificativa legal do empreendimento, que buscou analisar os impactos que podem ser provocados direta ou indiretamente sobre o meio ambiente. A avaliação dos impactos ambientais é um dos instrumentos da Política Nacional do Meio Ambiente, previsto no art. 10, da Lei Federal n. 6.938/8 . O quadro 1 e a figura 2 demonstram as mudanças que serão realizadas com as obras do Complexo Portuário. Em seguida as figuras 3 e 4 ilustram como é o acesso ao Complexo Portuário na atualidade.

Quadro 1- Larguras atuais e projetadas do canal de acesso

\begin{tabular}{|c|c|c|}
\hline Trecho do Acesso Aquaviário & Largura Atual & Largura Projetada \\
\hline Canal Externo & $160 \mathrm{~m}$ & $190 \mathrm{~m}$ \\
\hline Entre molhes & $135 \mathrm{~m}$ & $219 \mathrm{~m}$ \\
\hline Canal Interno & $165 \mathrm{~m}$ & $170 \mathrm{~m} \mathrm{a} \mathrm{200} \mathrm{m}$ \\
\hline Bacia de manobra & $165 \mathrm{~m}$ & $530 \mathrm{~m}$ \\
\hline
\end{tabular}

Fonte: Adaptado pelos autores a partir de SEP/PR (2013).

Figura 2- Projeção futura de acesso ao Porto após as obras no canal

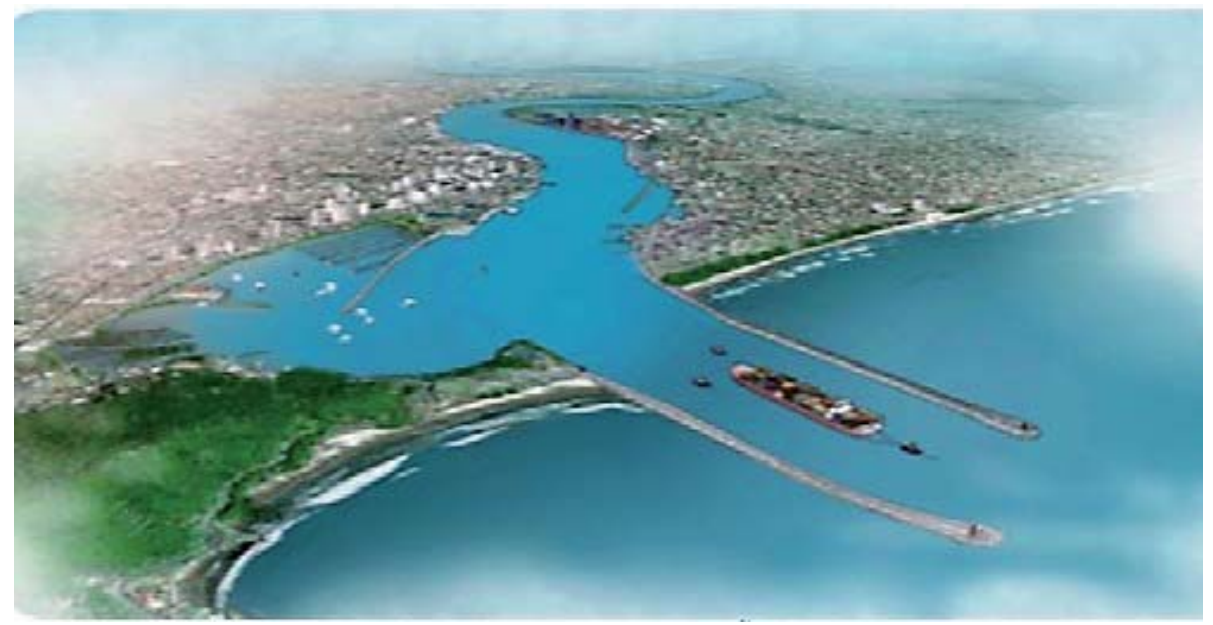

Fonte: SEP/PR (2013).

Figura 3- Acesso atual ao Complexo portuário do Rio Itajaí-Açu

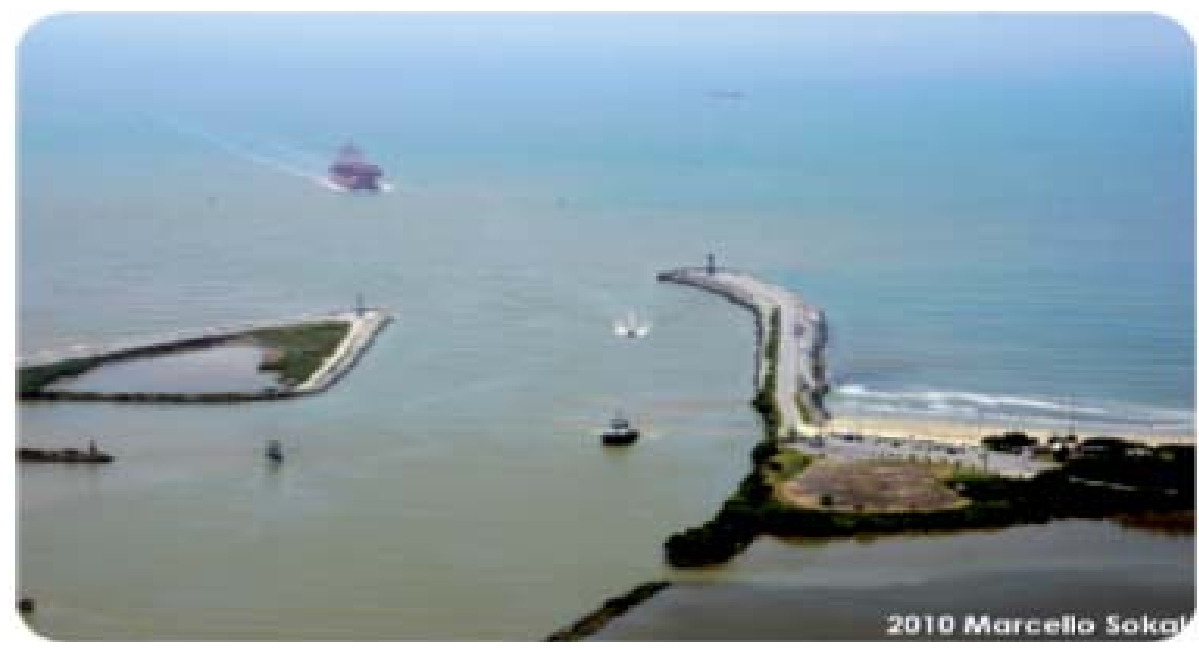

Fonte: SEP/PR (2013). 
Figura 4- Imagem atual e futura do acesso ao Complexo portuário do Rio Itajaí-açú
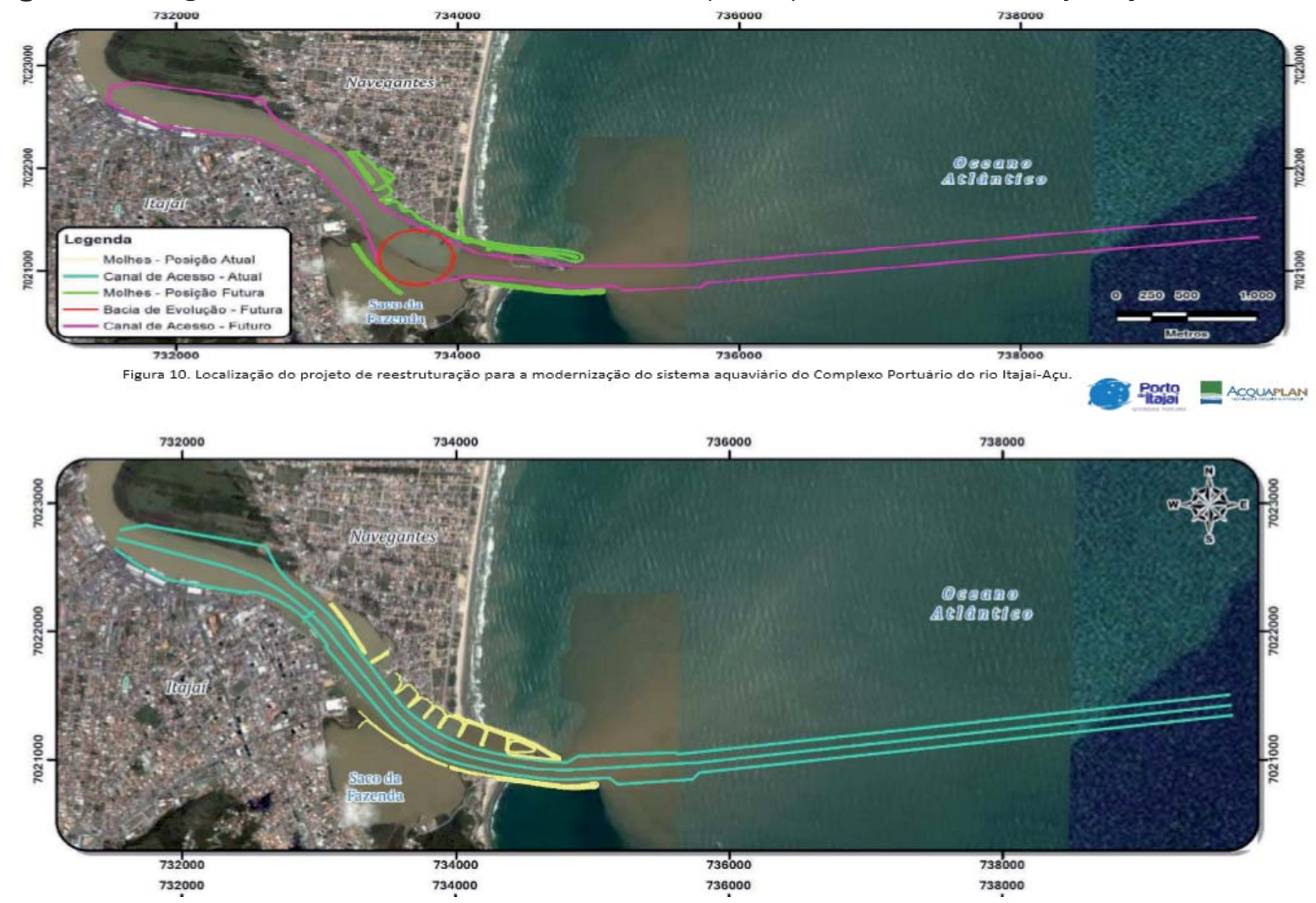

Fonte: SEP/PR (2013).

Dessa forma, ainda conforme o RIMA, a estrutura de contenção da nova bacia de evolução contempla a implantação de uma nova Bacia de Evolução adentrando, em parte, o ambiente denominado Saco da Fazenda, em Itajaí. Ela contará com um raio de 265 metros, com profundidade de 14 metros. Por bacia de evolução se compreende a área de manobras de um porto, onde os navios podem girar para atracar e desatracar com segurança.

Assim, a partir dos dados apontados, verifica-se a necessidade de buscar compreender quais impactos que essa construção/modificação do canal trará para a pesca artesanal, bem como, para a vida dos pescadores e para o meio ambiente como um todo; buscar relacionar os principais impactos ambientais, quais medidas compensatórias e mitigadoras, planos e programas ambientais que estão sendo pensados e criados a partir dessas mudanças. Verifica-se, a partir da fala dos pescadores, que a construção, mesmo que ainda no início, já está afetando a pesca, sobretudo, quantitativamente. Sobre o crescimento da cidade, eles foram unânimes em dizer que isso tem influenciado na pesca, mas que o que vem trazendo danos sérios seria a obra de dragagem do rio. Conforme o entrevistado S. (2016):

Não, não... o que tem interferido na nossa pesca é a dragagem do rio Itajaí ali, que tão aumentando, aí a draga vai lá fora, solta muita sujeira, toco, lama. Nós pegamos tudo na rede, passa muito trabalho né!? Tem mais de sete dragas dragando, ai eles passam tudo para aquela draga grande que joga tudo para o mar. Eles estão com aquela obra de expansão do rio. Que vão aumentar o rio e tão dragando.

Questionou-se se a obra seria apenas para aprofundar o rio ou também alargar o canal, e conforme o entrevistado S. (2016): 
É eles vão dragando, mas vão aumentar a boca lá também. Vão alargar para entrar navio maior. E essa questão também atrapalha quem pesca lá fora né, porque fica muito navio ancorado, e aí é perigoso, pois o navio não desvia. E cria aqueles buracos da âncora do navio sabe?! Que aí tu vais e cai num buraco daqueles. Num barquinho desses é raro tu conseguir tirar o aparelho e as redes, porque ela vai assim aberto. Ai ela ensaca aquela bola de lama que cai da âncora.

Percebe-se assim, que existe uma grande preocupação no que se refere à obra e que esta já vem trazendo alguns problemas aos pescadores. Sobre a Vila de Pescadores São Pedro, localizada na margem esquerda do Rio Itajaí-açú, o entrevistado S. (2016) respondeu que: "Não, tão mexendo em tudo, tanto é que queriam expulsar todo mundo de lá. Tão indenizando tudo".

Verifica-se, portanto, que existe certa discordância no que é relatado pelos entrevistados e o que consta no Relatório de Impacto Ambiental. Assim, é preciso que tais impactos sejam mais bem analisados e que se busque também ouvir, em uma ação participativa, aqueles que estão próximos do local da obra, os quais, concomitantemente, são os mais afetados, sendo estes, os pescadores artesanais.

\section{CONSIDERAÇÕES FINAIS}

A partir das alternativas contidas no Relatório do IPCC (2014), que incluem propostas de mitigação e adaptação para as mudanças climáticas, nota-se o quanto elas são importantes na contribuição e melhoria do ambiente em que se vive. São sugestões que levam em conta não somente o saber científico, mas também o saber empírico, ou seja, o saber popular. Essas estratégias ressaltam, entre outras ações, a importância da participação da sociedade e servem como estímulo e incentivo para a realização de trabalhos em conjunto, de modo que se atinjam meios de produção e existências mais sustentáveis. Isto porque, quando há uma preocupação coletiva sobre o que é melhor para o planeta, unem-se múltiplos saberes e inteligências, bem como uma gama infindável de conhecimentos. Tal fato faz com que as ações envolvam e comprometam a totalidade dos atores sociais, o que possivelmente acarreta maior efetividade.

Nota-se com o estudo o quão importante é buscar compreender também as pessoas que vivem em determinado espaço. Estas possuem o conhecimento que, muitas vezes, os cientistas desconhecem. Ao unirem-se diferentes conhecimentos, o aprendizado demonstra-se maior, mais rico e conectado à determinada realidade, pois esta é mais bem conhecida por quem a vivencia diariamente. A asserção demonstra-se fática, pois se verificou, mediante cotejo das entrevistas e de documentos oficiais, que existem muitas divergências entre o saber popular e o científico. Com o resultado da construção deste estudo, buscou-se identificar e apontar essas divergências. Assim, como já mencionado, demonstra-se a existência de pontos de divergência entre as afirmações do relatório do IPCC e as percepções dos pescadores do Rio Gravatá. Estas dizem respeito, sobretudo, à diminuição do número de peixes e à maior ocorrência de eventos climáticos extremos.

Ao serem questionados sobre o aquecimento global e suas implicações sobre o ambiente do entorno, afirma-se que este se mantém semelhante e que antigamente os eventos extremos ocorriam com mais frequência e severidade do que hoje. Como também mencionado, parece haver clara noção de que os vilões respondem pelo nome de civilização, os ditos homens que sabem que sabem (homo sapiens sapiens). Não é o mar que está avançando. Na verdade, são as pessoas que estão avançando sobre o mar, e isso vem trazendo sérios problemas, afirma um dos 
pescadores. Trata-se, para o mais singelo dos homens, de um fato perceptível. Para o capitalismo selvagem, não. No que se refere ao fato de as mudanças climáticas citadas pelo Relatório do IPCC (2014) já estarem em curso, de acordo com as entrevistas realizadas, elas não parecem tão perceptíveis ao olhar dos pescadores do Rio Gravatá. Faz-se importante ressaltar que é sabido que as mudanças climáticas são um fato. Isso deve fazer todos pensarem sobre o quão urgente é a busca por formas que transformem a atual situação de degradação ambiental e, assim, evitar que situações futuras se tornem cada vez mais catastróficas e irreversíveis para a manutenção do globo. Ao prosseguir semelhante descaso com o meio ambiente não apenas a vida humana está em risco, mas também a existência de tudo que vive. Por fim, a transformação precisa se iniciar localmente, mediante ações realizadas em conjunto, unindo-se diversificados saberes, para que assim se possam criar planos de ação, envolvendo a todos, desde a sociedade civil até o empresariado e o poder estatal.

\section{REFERÊNCIAS}

BRASIL. Lei n. 6.938, de 31 de agosto de 1981. Dispõe sobre a Política Nacional do Meio Ambiente, seus fins e mecanismos de formulação e aplicação, e dá outras providências. Disponível em: <http://www. planalto.gov.br/ccivil_03/leis/L6938.htm> Acesso em: 14 set. 2018.

BRAUN, Samara. O mar e a cidade: mudanças climáticas e o desenvolvimento urbano em Joinville (SC). 2017. 142 f., il. Dissertação (Mestrado em Desenvolvimento Regional)- Programa de Pós-Graduação em Desenvolvimento Regional, Centro de Ciências Humanas e da Comunicação, Universidade Regional de Blumenau (FURB), Blumenau, SC, 2017.

CAPRA, Fritjof. A teia da vida: uma nova compreensão científica dos sistemas vivos. São Paulo: Cultrix, 1996.

CHAVES, Tiago Fernando. Uma análise dos principais impactos ambientais verificados no Estado de Santa Catarina. Revista Gestão \& Sustentabilidade Ambiental, Florianópolis, v. 5, n. 2, p. 611-34, 2016.

FERREIRA, Morgana Francini; BEAUMORD, Antônio Carlos. Mapeamento da sensibilidade ambiental à derrames de óleo nos cursos de água da bacia do Rio Canhanduba, Itajaí, SC. Brazilian Journal of Aquatic Science and Technology, Itajaí, SC, v. 12, n. 2, p. 61-72, 2008.

GANUZA, Ernesto; OLIVARI, Lucrecia; PAÑO, Pablo; BUITRAGO, Luz; LORENZANA, Concepción. La democracia em acción: una visión desde las metodologias participativas. Espanha: Antigona, 2010.

INSTITUTO BRASILEIRO DE GEOGRAFIA E ESTATÍSTICA (IBGE). Cidades. 2017. Disponível em: <https:// cidades.ibge.gov.br/brasil/sc/navegantes/panorama>. Acesso em: 26 mar. 2018.

PAINEL INTERGOVERNAMENTAL PARA MUDANÇAS CLIMÁTICAS (IPCC). Sumário para os tomadores de decisão. Grupo de Trabalho II do IPCC - Quinto Relatório de Avaliação do IPCC, 2014. Disponível em: <http://www.iniciativaverde.org.br/biblioteca-nossas-publicacoes.php>. Acesso em: 21 jan. 2017.

PREFEITURA MUNICIPAL DE NAVEGANTES. Cidade. [s.d.]. Disponível em: <http://www.navegantes.sc.gov. br/l/cidade $>$. Acesso em: 11 dez. 2016.

SECRETARIA ESPECIAL DE PORTOS DA PRESIDÊNCIA DA REPÚBLICA (SEP/PR). Superintendência do Porto de Itajaí. Relatório de Impacto Ambiental (RIMA) para a reestruturação do canal de acesso ao complexo portuário do Rio Itajaí-Açu. AcquaPlan - Tecnologia e Consultoria Ambiental, 2013. 


\section{Sobre os autores:}

Diego dos Santos: Mestrando em Desenvolvimento Regional, pela Fundação Universidade Regional de Blumenau (FURB). Especialista em Controladoria e Auditoria pela UNIASSELVI/ FAMEBLU. Possui graduação em Desenvolvimento de Recursos Humanos pela Universidade do Oeste de Santa Catarina (UNOESC) e em Administração pelo Centro Universitário Franciscano do Paraná (FAE). Tem experiência na área de Recursos Humanos e de Administração. E-mail: dhieghobnu@gmail.com

Fabiane Krumreich Siefert: Mestrando em Desenvolvimento Regional pela Fundação Universidade Regional de Blumenau (FURB). Possui graduação em Serviço Social pela FURB. Tem experiência na área de Serviço Social, com ênfase em Serviço Social. E-mail: fafaks@uol.com.br

Gilberto Friedenreich Santos: Doutorado em Geografia Física pela Universidade de São Paulo (USP). Mestrado em Geografia pela Universidade Federal de Santa Catarina (UFSC). Graduação em Geografia pela UFSC. É professor do quadro da Fundação Universidade Regional de Blumenau (FURB). Atua em pesquisa na área de Geociências, com ênfase em Geomorfologia e História Ambiental. E-mail: gilbertofrieden@gmail.com

Cristiane Mansur Moraes de Souza: Pós-doutorado em Ciências Ambientais (bolsa CAPES) na Washington State University, Pullman, WA, EUA. Doutorado Interdisciplinar em Ciências Humanas pela Universidade Federal de Santa Catarina (UFSC). Mestrado em Urban Design Ma- Oxford Brookes University. Graduação em Arquitetura e Urbanismo pela UFSC. Pertence ao quadro permanente de professores do Programa de Pós-Graduação em Desenvolvimento Regional e do curso de Arquitetura e Urbanismo, ambos da Universidade Regional de Blumenau (FURB). É Alumni da Oxford Brookes University (UK) e da Washington State University Alumni Association (USA). Coordena o grupo de pesquisa "Análise Ambiental e Ecodesenvolvimento" cadastrado no CNPq. E-mail: arqcmansur@gmail.com 
